\title{
Faça um esforço por agradar: dicas para um trabalhador de sucesso segundo a Randstad e a Tempo-Team
}

\author{
José Nuno Matos \\ Licenciado e mestre em Ciência \\ Política pelo ISCSP-UTL, é doutorado \\ em sociologia no Instituto de Ciências \\ Sociais da Universidade de Lisboa \\ (ICS-UL), com a tese $O$ operário em \\ construção: das relações humanas \\ ao trabalho temporário. Encontra-se \\ presentemente a desenvolver um \\ projeto de pós-doutoramento em torno \\ da relação entre a prática jornalística e \\ a precariedade. Tem dedicado os seus \\ estudos às questões do trabalho, do \\ sindicalismo e dos movimentos sociais. \\ E-mail: jose.matos@ics.ulisboa.pt
}

Resumo: As novas formas de produção e as suas exigências vieram introduzir profundas alterações no mundo do trabalho e, logicamente, no trabalhador. Outrora selecionado pela força dos músculos e/ou por um conhecimento meramente técnico, ao trabalho da atualidade exige-se um conjunto de qualidades mais vastas, as quais obrigam a mobilização de traços de personalidade e sociabilidade. $\mathrm{O}$ objetivo deste artigo reside na compreensão do teor da contribuição correta e necessária que todo trabalhador deve desenvolver, concentrando-se a nossa análise no comportamento do trabalhador, em primeiro lugar, no processo de recrutamento e, posteriormente, na relação com os colegas e com o chefe. Com base nos artigos de imprensa e vídeos publicados na página de Facebook da Randstad e da Tempo-Team, procederemos ao estudo destas grelhas de inteligibilidade que devem orientar a conduta de todo trabalhador.

Palavras-chave: Trabalho; Redes sociais; Recrutamento; Curriculum vitae; Coach.

Make an effort to please: tips for a successful employee according to Randstad and Tempo-Team

Abstract: New forms of production and their demands have introduced profound changes in the world of work and, of course, in the worker. Once selected by the strength of the muscles and/or merely by their technical knowledge, the worker of today is required to embody a broader set of qualities which require the mobilization of personality traits and sociability. The aim of this article lies in understanding the content of the correct and necessary contribution that every worker should develop. We focus our study, firstly, on the behaviour of the worker in the recruitment process and, later, in the relationship with his colleagues and boss. Based on press articles and videos published on the Facebook page of Randstad and Tempo-Team, we will analyse these grids of intelligibility that should guide the conduct of every worker.

Keywords: Work; Social network; Recruitment; Curriculum vitae; Coach. 


\section{Introdução}

As últimas décadas têm sido marcadas por profundas mudanças na economia e no trabalho. A aplicação das novas tecnologias no domínio da produção, aliada à globalização transnacional dos mercados, permitiu a redução do número de trabalhadores industriais no mundo "desenvolvido", passando a grande maioria dos empregos a concentrar-se no setor terciário. Mesmo as indústrias que não se deslocalizaram, à procura de condições de investimento mais atrativas, alteraram os seus modelos de gestão e de trabalho, adaptando-os a todo um novo rol de exigências, tais como a qualidade, os prazos de entrega, a satisfação de exigências específicas, a inovação e diversificação dos produtos. O toyotismo, ao contrário do que acontecia nas velhas indústrias fordistas, tende a dispensar o esforço físico, doravante delegado nas novas tecnologias de produção, inaugurando uma polivalência de tarefas, compreendendo, cada uma, o manuseamento de várias máquinas e o diagnóstico, manutenção e controlo de qualidade da sua produção.

A introdução de novos elementos sociais no domínio produtivo-o conhecimento, a imaginação, a reflexão, a habilidade comunicativa ou até a emoção - vem desencadear no trabalhador, seja ele do sector secundário ou do terciário, uma diversidade de saberes quer teórico-práticos, quer relativos ao próprio ser. A sua procura por parte das empresas representa o fim do monopólio da qualificação como critério essencial de recrutamento, dando lugar a uma mais lata procura de competências. A par das hard skills, nas quais se englobam os conhecimentos sobre um domínio específico, o trabalhador passará a ser avaliado segundo as suas soft skills, traços e saberes menos formais, mas tão ou mais determinantes.

${ }^{1}$ Propriedade da multinacional holandesa Randstad, essas empresas são o resultado de um processo de concentração iniciado em 2008, com a aquisição das antigas Select e Vedior. A quota do mercado português então absorvida levou a Comissão Europeia a pronunciar-se sobre o negócio, fazendo depender a sua aprovação da colocação à venda das operações nacionais detidas pela Randstad, então adquiridas pela norte-americana Kelly Services, e do adiamento (durante um período de dois anos) da adoção da nova marca. Por conseguinte, foi apenas em 2010 que as antigas Select e Vedior se passaram a apresentar, respetivamente, como Tempo-Team e Randstad, tendo em 2012 o grupo decidido unificar a sua atividade através do uso exclusivo da marca Randstad Portugal.

${ }^{2}$ De acordo com informações disponibilizadas no seu sítio, as áreas de atuação incluem, entre outros, a administração, a hotelaria, o setor automóvel, os call centres, a aviação e o turismo, a banca e os seguros.

\section{${ }^{3}$ Análise das políticas de $\mathrm{RH}$} desenvolvidas pela empresa e aconselhamento, nas suas próprias palavras, sobre a flexibilidade ideal, sobre o processo de planeamento e sobre os métodos de trabalho pelos quais os custos indiretos podem ser reduzidos.
A relevância dessas qualidades implicará, como é lógico, o recurso a novas formas de recrutamento e seleção de trabalhadores. Até a Segunda Guerra Mundial, a avaliação partia da psicotécnica, isolando o indivíduo, sujeitando-o a uma série de estudos físicos e psicológicos e classificando-o apropriado (ou não) ao respetivo posto de trabalho. Atualmente, técnicas como a dinâmica de grupos ou o role-playing demonstram uma menor preocupação com a "medição, previsão e a performance laboral do que com relações, atitudes, interação, negociação, identidades e auto-perceção" (ILES; SALAMAN, 1995: 222). Porém, mais do que a utilização de uma ou mais técnicas de seleção específicas, é a introdução de novos tipos de vínculos contratuais, comummente designados de flexíveis, que vem garantir a perpetuação dos dispositivos de avaliação do indivíduo ao longo da sua permanência no mercado de trabalho. A substituição gradual do termo "emprego" pelo de "empregabilidade" remete, precisamente, para essa realidade. A noção de que o trabalho que se tem poderá ter uma longevidade limitada conduz a que o indivíduo esteja (ou, pelo menos, se sinta) sob avaliação permanente, desenvolvendo então os esforços necessários ao sucesso no mercado de trabalho. Nesse sentido, o emprego é avalizado como um momento integrado na condição total de empregável.

\section{Metodologia}

Os artigos e vídeos que compõem o nosso objeto de estudo visam confrontar o leitor com um conjunto de técnicas e/ou de opções apresentadas como receitas para uma empregabilidade superior. Editadas por sítios temáticos disponibilizados por meios de comunicação social (como o Isabe, do Jornal i) ou portais de emprego - o Sapoemprego ou o Expressoemprego -, as peças foram recolhidas a partir de uma observação não participante das páginas de Facebook das empresas Randstad e Tempo-Team ${ }^{1}$, com atividades nas áreas do trabalho temporário ${ }^{2}$, de serviços de consultoria (os serviços in-house) ${ }^{3}$ ou ainda de soluções de subcontratação/outsourcing, em particular ao nível dos call centres. O recurso a redes sociais, como o Facebook, contribui para o reforço do sentido veiculado pelos artigos. O cariz do próprio dispositivo, usado enquanto um meio de interação entre empresa, trabalhadores, candidatos e demais interessados, 
${ }^{4}$ A noção de performatividade na linguagem terá sido inicialmente desenvolvida por Austin. O enunciado performativo, na sua visão, compõe o próprio ato, dependendo a sua eficácia das condições de felicidades existentes, do contexto em que decorre ao tom adotado na sua entoação. Autores como Bourdieu (1998) ou Benveniste (1992) teceram críticas à secundarização dos poderes e dos capitais entre as condições de felicidade. Se a capacidade de falar é universal, a capacidade de ser ouvido - mais do que isso, de se ver reconhecido socialmente o sentido desse mesmo falar - está longe de o ser.

${ }^{5}$ À semelhança do discurso escrito, a análise dos vídeos publicados no Youtube tenderá a enfatizar a sua componente social, em particular as formas e conteúdos de demonstração, classificação, nomeação.

${ }^{6}$ Programa com ligação na página de Facebook da Tempo-Team a 4 jul. 2011. através do qual se pode aceder a informação de forma gratuita, podendo até trocar opiniões a respeito, ajuda a criação de uma espécie de espaço sociossimbólico. Tanto a configuração discursiva dos artigos analisados, sob a forma de conselhos, manuais práticos e "dicas", como o seu meio de divulgação, partilhado entre "amigos" e "fãs", contribuem para um exercício mais eficaz do poder performativo sob o leitor, isto é, a criação das condições para que o indivíduo se reconheça no diagnóstico realizado e, associado, nas receitas sugeridas ${ }^{4}$.

O presente estudo não reside tanto numa análise com base na linguística e na semiótica, centrando-se antes na relação entre discurso e sociedade. Em termos práticos, essa opção tende a secundarizar o texto e/ou a imagem ${ }^{5}$ em nome da interação de instituições, práticas e "produção de sujeitos particulares" (ROSE, 2002: 164). O nosso estudo compreende assim uma metodologia que visa a identificação de pontos que atravessam os vários discursos (arquivo). Não o cumpre, porém, mediante uma observação isolada, visando antes "todo esse domínio de instituições, dos processos económicos, das relações sociais nas quais uma formação discursiva se pode articular", demonstrando como "a autonomia do discurso e a sua especificidade nem por isso lhe dão um estatuto de pura idealidade e de total independência histórica" (FOUCAULT, 2005: 213). O discurso será, certamente, considerado a partir da sua forma, mas sempre com base no regime de verdade em que se insere, em quem o reproduz e em que âmbito é que o faz.

\section{A “boa apresentação" do eu na vida quotidiana: a procura ativa de emprego}

A procura de emprego não ocupa, atualmente, uma posição fixa na trajetória social e laboral de cada pessoa. Se há uns anos seria possível identificar o seu lugar entre o término dos estudos e a obtenção de emprego, hoje é difícil fazêlo. Ela decorre ainda no período de ensino, seja por via de estágios curriculares obrigatórios e voluntários, seja determinado pelas necessidades económicas do estudante-trabalhador. O fim das promoções automáticas, a não circunscrição a uma empresa e a oscilação de períodos de emprego e de desemprego evidenciam a erosão do conceito clássico de carreira, passando esta a ser composta por uma diversidade de experiências e não, como antes, por uma só experiência delimitada no espaço e no tempo. A procura ativa de emprego adquiriu assim uma enorme perenidade, inclusive entre categorias até agora insuspeitas: estudantes, reformados e empregados em busca de uma segunda remuneração ou de melhores condições contratuais.

Contabilizadas as devidas diferenças, essa demanda obriga a uma série de medidas práticas, significantes de uma postura face aos desafios, frequentemente descritas e enumeradas em artigos cujos títulos remetem para receitas instrutórias - "Como procurar...", "Dicas para...", “O ABC de...". Seguindo a sua lógica de raciocínio, procuraremos analisar os passos que separam o candidato do acesso à oportunidade.

A primeira etapa corresponde, na realidade, a uma fase prévia de preparação, na medida em que, como se pode ler no Guia Interativo do IEFP Como procurar emprego ${ }^{6}$, a pesquisa deve ser "persistente e organizada", exigindo "tempo, energia, vontade e persistência". As medidas a empreender supõem, portanto, um período de reflexão em que se começa por "trabalhar as três regras básicas: conhecer-se a si próprio, conhecer o mercado de trabalho e conhecer as técnicas de procura de emprego". Segundo essa ordem, o trabalhador deverá pensar "nas atividades que sabe fazer e nas competências que possui", bem como nos "seus gostos e interesses" e na "eventual necessidade de atualizar conhecimentos e competências profissionais". Desse ponto, parte-se para a consulta de estatísticas e de ofertas de emprego nacionais e internacionais, quer através de vias formais (centro de emprego, internet, ETT, entre outras), quer pelo recurso a "familiares, amigos e conhecidos para obter informações sobre oportunidades de emprego" (IEFP, [s.d.]) e, em último, para a produção do curriculum vitae (CV). 
${ }^{7}$ Artigo com ligação na página de Facebook da Randstad a 17 dez. 2010.

${ }^{8}$ Artigo com ligação na página de Facebook da Randstad a 19 out. 2011.

${ }^{9}$ Artigo com ligação na página de Facebook da Randstad a 20 set. 2011.

${ }^{10}$ Artigo com ligação na página de Facebook da Tempo-Team a 14 abr. 2011
Embora não represente, per si, uma garantia, o CV "pode abrir uma porta para uma entrevista, numa altura em que os números do desemprego em Portugal têm vindo a aumentar" (Ibid.), justificando assim uma cuidada redação. No seu Guia do colaborador, a Randstad Portugal sugere a sua divisão em cinco partes obrigatórias: os dados pessoais, "quanto basta para uma identificação"; o último nível de escolaridade; a experiência profissional, da "mais recente para a mais antiga"; a formação, com destaque para as mais relevantes; e as aptidões específicas, com atenção para o "conhecimento de línguas e informática". O candidato poderá ainda optar pela menção das suas atividades de lazer, pois "isso também revela ao potencial entrevistador como somos e como nos posicionamos no mundo" e eventuais referências de "pessoas que podem atestar que somos bons profissionais" (O PRIMEIRO..., 2010: 10) ${ }^{7}$.

Essas informações deverão ser apresentadas em poucas páginas, concisas e organizadas, facilitando o trabalho do responsável pelo seu exame. De forma a espelhar a vontade e firmeza do retratado, a narrativa deverá privilegiar "verbos na voz ativa, que indiquem determinação: alcançar, ganhar, aprender, servir, arranjar, encorajar" ou termos como "primeiro, único, melhor" (UM CURRÍCULO..., [s.d.]) e e, na mesma lógica, evitar verbos conjugados no passado ou passivos, incompatíveis com a transmissão de uma "ideia de ação e presente" (PALAVRAS..., [s.d.]) $)^{9}$. O Guia de carreira da SapoEmprego aconselha ainda a eliminação de termos com uma carga negativa, como "agressivo, mau, limitação, erro, nada, pânico, problema", de clichés, como "dinâmico, responsável e criativo", de adjetivos que "perderam a sua relevância por serem repetidos até a exaustão", ou ainda, além de erros de ortografia e de construção frásica, de abreviaturas, repetições ou bengalas de linguagem (Ibid.). Igualmente relevantes, existem uma série de elementos estilísticos - a fonte de letra, a fotografia ou a referência a um blogue ou página pessoal, a título de exemplo - cuja consideração poderá ser determinante. É importante realçar, todavia, que tanto esses componentes, como o próprio conteúdo, devem responder a situações específicas, adaptando-se à empresa e ao posto de trabalho.

Por fim, aliando a maior e mais célere capacidade de envio a um sentido inovador, o CV deverá poder ser consultado on-line. Os diversos formatos associados à internet vêm abrir um vasto leque de campanhas de marketing pessoal, fazendo com que a sua capacidade de manipulação se torne num critério de avaliação. A criação de um perfil profissional em redes sociais especializadas, como o Linkedln, o Branchout (Facebook) ou o Twitter, e a procura e interação com outros "perfis" veio a tornar o CV (pelo menos, na sua forma tradicional) algo completamente ultrapassado. Nas redes sociais, como defende o docente e especialista em marketing digital Filipe Carrera,

as pessoas são encontradas não porque pura e simplesmente se mostraram, mas pela partilha. Eu partilho e respondo àquelas questões e ajudo pessoas, eu crio eventos, etc. Eu torno-me visível, eu apareço no radar [...] Isto porque ao partilharmos algo com outras pessoas, elas assumem que somos especialistas na área. Assumem-no, à partida, porque quando você adota o conselho de alguém e esse conselho resulta, o que é que você diz aos seus contatos sobre essa pessoa? Que ela sabe! A partilha de conhecimento, quando alguém manda um e-mail a perguntar como se faz e eu ajudo, dedico tempo a responder, e de repente as coisas começam a acontecer, porque nós ficamos sempre com uma ótima impressão de alguém que nos ajuda sem à partida nos pedir logo "isso custou X". Achamos extraordinário. E passamos muito a palavra. Tanto no online como no offline (O VELHO..., 2011) ${ }^{10}$.

O "CV" passa a incluir todo o mais pequeno ato realizado pelo candidato na rede. Os contactos estabelecidos e o seu modo de gestão, a partilha realizada, até o seu modo de apresentação, são dados em tempo real, submetidos a uma constante avaliação e, portanto, merecedores de um certo cuidado: 
${ }^{11}$ Numa reportagem sobre redes profissionais, Cátia Mateus menciona a importância da sua consulta no momento de recrutamento: "Antes de entrevistar um candidato ou no momento em que é analisado o seu perfil, não há diretor de recursos humanos que não espreite as respetivas páginas nas redes sociais. Um estudo recentemente divulgado pela Right Management revela que o Facebook já conseguiu superar o Linkedin, tornandose em todo o mundo a rede favorita dos headhunters para aquele momento de 'tira-teimas' que antecede qualquer contratação. E os resultados desta análise podem ser muito assustadores para os candidatos, já que, nos Estados Unidos, $70 \%$ das empresas inquiridas confessam já ter desistido de um candidato depois de analisar a sua página pessoal nas redes sociais" (MATEUS, 2011c). Artigo com ligação na página de Facebook da Tempo-Team a 17 dez. 2011.

${ }^{12}$ Artigo com ligação na página de Facebook da Tempo-Team a 25 jun. 2011.

${ }^{13}$ Artigo com ligação na página de Facebook da Tempo-Team a 24 jun. 2011.

${ }^{14}$ No vídeo, o candidato encara a personagem de um multimilionário excêntrico, apresentando-se de bigode postiço, casaco e cuecas e, de forma humorística, descrevendo as suas competências sociais. No final, pede à Google que analise o seu CV e lhe conceda uma conversa de 15 minutos (MATEUS, 2011b). Artigo com ligação na página de Facebook da Tempo-Team a 12 out. 2011.

${ }^{15} \mathrm{O}$ jovem setubalense Marco Serra optou por recorrer à impressão de uma $t$-shirt com a frase "Procuro Trabalho», acompanhada do seu contato e declaração de competências do IEFP (Pereira, 2011). Artigo com ligação na página de Facebook da Tempo-Team a 25 jul. 2011.

${ }^{16}$ Artigo com ligação na página de Facebook da Tempo-Team a 01 jun. 2011.

${ }^{17}$ Alguns artigos chegam a recomendar a entrega pessoal do CV junto das instalações da empresa.

${ }^{18}$ Artigo com ligação na página de Facebook da Tempo-Team a 23 fev. 2011.

${ }^{19}$ Artigo com ligação na página de Facebook da Tempo-Team a 17 nov. 2011. fiz um projeto o ano passado [...] em que fui a várias universidades explicar que eles estão, no fundo, a determinar o seu futuro. Todas as idiotices que colocarem na Web vão ser perseguidas durante muitos anos. Isto não quer dizer que temos de ter uma atitude esterilizada. Basta ver o meu próprio Facebook, eu estou lá, em festas, e não sei que mais, porque isso faz parte de quem sou, mas não ponho no meu Facebook determinados detalhes da minha vida que ninguém sabe (Ibid. $)^{11}$.

A aplicação Branchout, disponível aos utilizadores do FB, chega mesmo a permitir a emissão de recomendações, depoimentos e até distinções: "Você é rankeado de acordo com elas, e quanto mais conexões você tiver - com pessoas e com empresas - mais importante fica na lista de pessoas influentes" (PEREIRA, 2011) ${ }^{12}$.

Uma vez integrado na rede, o CV pode assumir novos formatos, como o mini podcast áudio; o visual CV, transformado em página on-line; ou o vídeo-CV, a partir dos quais, na opinião de Conceição Pereira (Randstad), se podem "avaliar competências como a criatividade, a capacidade de comunicação e de expressão num estádio preliminar do processo, sendo valorizada em funções onde estas competências sejam críticas para o perfil que se pretende selecionar" (apud BARROSO, 2011) $)^{13}$. Dessa forma, o documento deixa de corresponder apenas a um espaço visual inerte onde a informação é reunida. De vídeos humorísticos, como o realizado por Matthew Epstein, autor de Googlepleasehireme ${ }^{14}$, a certificados impressos em $t$-shirts ${ }^{15}$, o importante é fazer da sua forma o conteúdo comprovativo de um saber técnico e criativo.

A acompanhar o CV, ou inserido nele, o candidato é aconselhado a enviar uma carta de motivação, exprimindo as razões da sua escolha. A concretização do seu objetivo, "convencer o empregador a chamá-lo para uma entrevista", torna alguns procedimentos obrigatórios: a remissão a uma pessoa e não apenas a um cargo, a síntese da narrativa, com "frases curtas e dinâmicas com muitos verbos ativos", ou a atenção a alguns elementos estéticos (uma boa frase de abertura e de final, evitando banalidades ou "frases feitas"). O foco, porém, reside no tom de entusiasmo com a oportunidade e, correspondentemente, na exclusão de temáticas que possam anular o seu efeito, como o salário, "senão acredite que vai criar uma impressão negativa" ou a falta de experiência profissional, mencionando antes "a sua capacidade de aprender depressa" (Expressoemprego, [s.d.]) ${ }^{16}$.

Editados e enviados os documentos, a resposta terá que ser procurada através do contacto direto com a empresa ${ }^{17}$, de preferência pessoalmente. Mesmo que se revele infrutífera, essa via cria oportunidades de diálogo e conhecimento com novas pessoas. Em alguns países, esse tipo de networking acabou mesmo por ultrapassar as fronteiras das empresas e da própria internet, decorrendo em cafés, restaurantes e até mesmo discotecas, espaços nos quais se trocam "contactos, informações sobre vagas e até pontos de vista sobre o mercado laboral, enquanto se come" (COMO ARRANJAR..., 2011) $)^{18}$.

Tanto num ambiente informal, mas ainda assim aglutinador de contactos, como na entrevista de emprego, estágio final do processo de recrutamento e seleção, as primeiras impressões são consideradas decisivas, sendo suficientes para se "fazer uma radiografia completa da pessoa" (MATEUS, 2011a)19. Causar uma boa impressão, segundo as recomendações publicadas, compreende uma relevância fundamental, exigindo cuidados prévios. Perante a marcação de uma entrevista de emprego, importa, em primeiro lugar, antecipar o seu momento, preparando-se para algumas questões relativas à sua condição, realizadas com base na análise do CV (e/ou do perfil on-line), ao grau de conhecimento da empresa e do seu segmento de mercado. O estudo do modo de apresentação assume uma importância equivalente, devendo o entrevistado optar nem por algo muito casual, significante de desleixo e falta de dedicação, nem por algo excessivamente formal, evitando "aparecer mais bem vestido do que o seu 
${ }^{20}$ Artigo com ligação na página de Facebook da Tempo-Team a 08 abr. 2011.

${ }^{21}$ DICAS para uma entrevista de emprego bem sucedida. iSabe, [S.I.], [s.d.]. Disponível em: <http://bit.ly/2j81fMM>. Acesso em: 20 dez. 2011. Artigo com ligação na página de Facebook da Randstad a 1 set. 2011.

${ }^{22}$ Artigo com ligação na página de Facebook da Randstad a 25 maio 2011.

${ }^{23}$ Uma opinião não inteiramente consensual entre as várias peças consultadas. Atendemos à posição de Joana Petiz: “Ok, está a candidatar-se ao emprego com que sempre sonhou. Mas isso não significa que deve aceitar todas as condições que lhe impuserem. Este é o momento para pôr as cartas todas na mesa: diga quanto espera receber e mostre-se disponível para negociar dentro de determinados limites. Subvalorizar-se pode levar o seu potencial chefe a pensar que afinal talvez não seja tão bom quanto quer vender-se. Além disso, não é de esperar que seja aumentado tão cedo, por isso há que pensar bem antes de se contentar com um salário apenas razoável - mesmo que seja mais do que recebia no seu anterior emprego. Lembrese que o último ordenado lhe pode servir de referência, mas se considerava que não era bem pago, não deve aceitar receber apenas mais umas migalhas, sob pena de, rapidamente, ficar insatisfeito com as condições de trabalho ou sentir que está subvalorizado. Exponha as suas capacidades e mais-valias e explique clara e concisamente por que razão pensa que deve receber determinado salário" (2011).

${ }^{24}$ PROCURA emprego? Ser licenciado já não ajuda. Agência Financeira, [S.I.], 2011. Disponível em: <http://bit.ly/2irXRNY>. Acesso em: 15 nov. 2011.Artigo com ligação na página de Facebook da Randstad a 19 jul. 2011.

${ }^{25} \mathrm{COMO}$ se dar bem numa entrevista de grupo. iSabe, [S.I.], [s.d.]. Disponível em: <http://bit.ly/2inTMY9>. Acesso potencial chefe" (PETIZ, 2011) ${ }^{20}$. Pormenores como "unhas, maquilhagem, barba feita, cabelo" (DICAS..., [s.d.]) ${ }^{21}$ veem-se igualmente dotados de poder simbólico, merecendo por isso alguma atenção. No dia da entrevista, é fundamental, antes de tudo, comparecer 15 minutos antes da hora apontada, evitando o atraso e a consequente transmissão de "uma ideia de irresponsabilidade" (Ibid.). Ao dirigir-se ao entrevistador, o candidato deve responder ao seu cumprimento com "um aperto de mão, firme e acompanhado de um sorriso" (POSTURA..., [s.d.]) 22. A linguagem corporal é, desse prisma, tão indispensável quanto a narrativa a desenvolver. A cabeça erguida, uma posição hirta (mas não rígida), a ligeira inclinação do corpo para a frente, o olhar frontal, até o tom de voz, tornam-se indicadores de confiança, atenção ou segurança. Num sentido inverso, cruzar as pernas, baloiçar a cadeira, bater com o pé no chão, gesticular em excesso, mexer no cabelo, roer as unhas ou olhar para o relógio serão interpretados como sinais ou de um "à-vontade" a mais ou de nervosismo e inquietação (Ibid.).

Sem se deixar vergar, pois "ninguém quer uma alforreca no escritório", é importante que o candidato não deixe de se apresentar "entusiasmado, motivado, perseverante, com espírito de iniciativa e disposto a aprender". A paixão pelo trabalho a desempenhar ou o orgulho no seu percurso profissional constituem, certamente, pontos a favor, desde que acompanhados pela revelação dos defeitos; por isso, "quando lhe perguntarem sobre as suas fraquezas - o que é cada vez mais frequente nas entrevistas - não minta" (PETIZ, 2011). A frontalidade, clareza de exposição e até debate de ideias, sem a necessidade de "concordar com tudo o que o entrevistador Ihe diz", devem ser uma constante ao longo da entrevista. Existem, porém, ressalvas a considerar, como o salário, a não mencionar "a não ser que lhe seja perguntado" 23, os benefícios, abordados "de forma discreta", ou eventuais experiências profissionais negativas - "Dizer mal só o vai prejudicar" (PROCURA..., 2011)²4.

Alguns processos de seleção submetem ainda os seus participantes a testes práticos e/ou à presença conjunta de outros candidatos, "uma forma das empresas compreenderem como você é a lidar com os outros o que, por sua vez, prova como é a trabalhar em equipa" (COMO SE DAR..., [s.d.]) $)^{25}$. Sob esses condicionalismos, e uma vez que a troca de argumentos decorre entre diversos interlocutores, a determinação, autenticidade, conhecimento, otimismo e simpatia assumem uma ainda maior relevância. No final, "com esse sorriso laroca e ar confiante todos lhe vão achar graça, inclusive os selecionadores" (Ibid.) ${ }^{26}$.

\section{O trabalho e "um ombro amigo"}

O sucesso no processo de seleção não implica, porém, o fim das operações de avaliação. Estas, ao atravessarem toda a relação de trabalho, conduzem a uma perpetuação da atenção e dos cuidados do trabalhador tanto consigo próprio como com os seus colegas e superiores hierárquicos.

A aparência, como sublinha o consultor e palestrante Mario Persona, continua a requerer um cálculo relevador de algum

cuidado e sensatez [...], pois um Office-boy que se queira vestir como diretor ou um gerente que queira trabalhar de bermudas ou de camiseta são igualmente atitudes estranhas, dependo também da filosofia da empresa. O melhor mesmo é não chamar muito a atenção para a roupa e para os adereços - joias, bijuterias, para que o talento e a capacidade sejam os elementos que ocupem o lugar sobre os holofotes. Pessoas exageradamente maquiadas, enfeitadas, tatuadas, vestidas de forma espalhafatosa, levam mais tempo para revelar a sua capacidade, porque vai demorar mais tempo para que os outros se acostumem com a sua aparência e passem a enxergar o que realmente importa nelas ${ }^{27}$.

A salvaguarda alarga-se aos modos de exposição oral, acautelando-se um tipo de "linguagem chula, gírias" (Ibid.), semelhante à utilizada entre o círculo de amigos. 
em: 21 nov. 2011.Artigo com ligação na página de Facebook da Randstad a 23 fez. 2011.
${ }^{26}$ Paralelamente a uma condução positiva, ambas as páginas de FB apresentavam artigos preventivos, ou seja, com a descrição das condutas a evitar por parte dos candidatos. Uma grande parte adota um teor humorístico, frequentemente baseado em situações verídicas. 27 Vídeo com ligação na página de Facebook da Randstad a 15 nov. 2011.

${ }^{28} \mathrm{O}$ artigo tem a particularidade de recomendar a aplicação das "suas ideias por conta própria” (Ibid.) caso não despertem atenção junto dos superiores. Artigo com ligação na página de Facebook da Randstad a 24 ago. 2011.

${ }^{29}$ Essas atividades, por norma, são organizadas por empresas contratadas para o serviço.

${ }^{30}$ Ao analisar as práticas do futebol desenvolvidas pelo Clube BCP, Nuno Domingos realça o quão a natureza coletiva do futebol pouco se compadece com a conceção individualista que hoje reina no mundo empresarial. Como tal, e relativo às atividades acima mencionadas, "não é por acaso que todos os novos desportos, independentemente das suas vantagens, são embrulhados no discurso da superação individual, da competição, da motivação. No fundo, trata-se de um discurso idêntico ao formulado no interior das empresas" (DOMINGOS, 2004: 326).

${ }^{31}$ Artigo com ligação na página de Facebook da Randstad a 6 out. 2011.

${ }^{32}$ Artigo com ligação na página de Facebook da Randstad a 18 ago. 2011.
Ter imaginação é, nessa perspectiva, tão relevante quanto saber "vender as suas ideias" de uma forma simpática e humilde - "Não precisa de ser cínico, mas faça um esforço por agradar. Quando apresentar as suas ideias, faça-o sem minimizar as ideias de ninguém. Todas as ideias são boas e é ao seu chefe que cabe avaliá-las e ver se podem ser postas em prática" (VENDA..., [s.d.]) $)^{28}$.

A qualidade das relações sociais é, aliás, um importante elemento de uma estratégia de marketing pessoal. Por norma, de acordo com o diagnóstico de Mário Persona, o primeiro impulso do recém-contratado "é entrar logo no grupo dos menos cotados na empresa e fazer amizade justamente com aqueles que podem parecer mais legais, mas que não são bem vistos pela chefia e pelos colegas" (NOVO..., 2009). A primazia da capacidade analítica sobre o instinto, hábil na descoberta dos "colegas que são benquistos pela chefia e quais os que são considerados medíocres, os que estão com o emprego por um fim, principalmente por problemas de caráter e comportamento" (Ibid.), impõe-se assim como chave de sucesso. A avaliação do comportamento do trabalhador em grupo poderá ocorrer, inclusivamente, fora do espaço da empresa. O relevo do "espírito de grupo" no índice de produtividade das empresas veio diversificar as técnicas de motivação, em particular a organização de acções de team-building, em geral atividades desportivas, como orientação, paintball ou canoagem, por exemplo ${ }^{29}$. O seu objetivo é dotar a lógica de divisão e competição de algum sentido lúdico, fundindo trabalho com lazer ${ }^{30}$. Desse modo, os atributos requeridos pelas práticas e o eventual ambiente de descontração passam a integrar a estrutura da empresa, reforçando as softskills e ajudando a mitigar possíveis disfunções, como as provocadas por equipas recém-formadas ou por conflitos internos $(\text { TEAM..., [s.d.] })^{31}$. Decorrendo quase sempre fora do horário de expediente, o team-building vem estender o lugar da empresa no espaço e tempo de vida do trabalhador. O convite (a ter que aceitar) é o de "ir para fora cá dentro", ou seja, de auferir de um maior grau de informalidade sem abandonar por completo o modo de apresentação adequado.

Ao mesmo tempo, esse tipo de atividades vem retirar o monopólio da avaliação a um grupo de técnicos especializados. As suas funções passam a ser fundamentadas por uma opinião coletiva em permanente atualização, capaz de incidir sobre o mais pequeno ato e, assim, de recolher os benefícios de um trabalhador que se sente sob permanente peer review (MCKINLAY; TAYLOR, 1998). Um poder, enfim, com o condão de conseguir multiplicar os olhares inspetivos, não mais concentrados sob um centro único e de fazer dos observadores observados.

A prossecução desse raciocínio torna a boa relação com os colegas e aproximação às chefias em dados lógicos e autoevidentes. Seria injusto, todavia, atribuir esse poder racionalizador a apenas um dispositivo quando, na verdade, ele é fruto da inter-relação de diversos. A própria natureza técnica da produção reforça o trabalho em coletivo, o qual, por coerência, passa a ter o estatuto de competência (se bem que dificilmente analisada de forma insulada, não só por nascer de uma obra conjunta, mas por resultar de uma interdependência com outro tipo de competências). Daí, a promoção das equipas de trabalho e, associada, a alteração das formas de chefia.

Apresentado como parte integrante desse leque de mudanças, o coaching pretende fundir o chefe com o técnico e o pedagogo. Qual treinador, como indicia a sua nomenclatura, o coach é "alguém que 'transporta' uma pessoa de um ponto de conhecimento/ação para um outro ponto diferente, mais elevado" (TORRES; DUARTE, 2011) 32 . O processo compreende uma formação prática, sob orientação permanente, com as suas linhas de contorno a ultrapassar a aprendizagem puramente técnica. Ainda que hierárquica, a posição anunciada é a do par, nas palavras da jurista Cláudia Torres e da docente Alzira Duarte, aquela que "funciona como modelo e apoia de forma incondicional o sucesso de quem ajuda. 
${ }^{33}$ Sob esse desígnio, a APG, com o apoio da Randstad, foi responsável pela iniciativa Passaporte RH. Nesse âmbito, um conjunto de estagiários era selecionado para trabalhar com um conjunto de mentores. O objetivo, segundo Catarina Horta (Randstad), é "replicar uma coisa que tinha acontecido connosco, com muitos de nós, que, enfim, nós tínhamos entrado em empresas e fomos estagiários de outros. E percebemos que muitos de nós, diretores de recursos humanos, tínhamos sido promovidos através de conhecimentos e através de experiências de outras pessoas.

Quisemos replicar esta experiência: se nós acolhêssemos não só o estagiário, mas fôssemos responsáveis pelo seu desenvolvimento na aquisição de competências de recursos humanos e também na sua empregabilidade, se conseguíssemos também que eles seguissem um percurso profissional nesta área". Vídeo com ligação na página de Facebook da Randstad a 14 dez. 2010.

${ }^{34}$ SAIBA como lidar com um chefe workaholic. iSabe, [S.I.], [s.d.]. Disponível em: <http://bit.ly/2jEt6mE>. Acesso em: 2 dez. 2011.Artigo com ligação na página de Facebook da Randstad a 19 maio 2011.

${ }^{35}$ Artigo com ligação na página de Facebook da Randstad a 10 mar. 2011.

${ }^{36}$ Artigo com ligação na página de Facebook da Randstad a 04 abr. 2011.

${ }^{37}$ DOMINE a arte da negociação.

iSabe, [S.I.], [s.d.]. Disponível em: <http://bit.ly/2j7YyuQ>. Acesso em: 21 nov. 2011.Artigo com ligação na página de Facebook da Randstad a 10 jul. 2011.

${ }^{38}$ COMO abordar o tema férias com o seu chefe. iSabe, [S.I.], [s.d.]. Disponível em: <http://bit.ly/2jrv5f9>. Acesso em: 29 nov. 2011. Artigo com ligação na página de Facebook da Randstad a 25 mar. 2011.

${ }^{39}$ COMO abordar o tema férias com o seu chefe. iSabe, [S.I.], [s.d.]. Disponível em: <http://bit.ly/2jrv5f9>. Acesso em: 29 nov. 2011. Artigo com ligação na página de Facebook da Randstad a 25 mar. 2011.
[...] que acredita no potencial de cada um e que a cada momento cria condições para demonstrar que este é alcançável e até mesmo superável” (Ibid.). Em suma, aquele com quem contamos para partilhar ideias e sugestões, pedir ajuda ou mesmo reconhecer erros ${ }^{33}$.

O imaginário do coach é, porém, contraposto por uma série de artigos em que a representação da hierarquia se encontra mais próxima da sua concepção tradicional. Uma dessas peças, a título de exemplo, enumera um conjunto de truques a aplicar num chefe workhalic. No seu cômputo geral, a fórmula revertese na gestão de um dado adquirido: demonstrando que se "é capaz de suar a camisola e que se preocupa" e, no momento exato, parar - "talvez ele se aperceba do quanto já se fartou de trabalhar e que agora é hora da pausa"; comprovando "a sua lealdade à empresa"; mantendo-o ocupado com relatórios, de forma a evitar "que ele esteja sempre a perguntar-lhe o que anda a fazer"; comunicando a sua situação aos recursos humanos; ou recusando-se a atender "chamadas do trabalho ao fim de semana ou quando acaba o dia no escritório"34. A cordial relação com o chefe chega a ser definida como algo que "às vezes pode ser difícil", mas que caso se queira "progredir na carreira e manter a sanidade mental é melhor tentar" (MENDES, [s.d.]) 35 . Assinado por Solange Mendes, o artigo começa por recomendar o estudo do chefe, não porque valha "a pena confrontá-lo. Isso só trará mauestar desnecessário", mas para perceber e "contrabalançar as falhas do boss". A perspectiva é, pois, a de apoio "nas decisões difíceis. Afinal, vocês são uma equipa", a de antecipação de problemas, a de apresentação de soluções e a de ganho de confiança: "Demonstre ser uma pessoa íntegra. Ofereça ao seu chefe um ombro amigo. Vai ver que ganha-Ihe a confiança mais depressa do que julga" (Ibid.).

Algumas matérias de elevada sensibilidade, como o salário ou as férias, são dignas de apontamentos específicos. Nestes, começa-se por recomendar ao trabalhador uma análise da sua prestação, base a partir da qual enformará o seu argumento. No "pedido" de aumento salarial convém que se apresente provas sólidas: os objetivos atingidos, as metas superadas, a contribuição para o sucesso da empresa, os feedbacks obtidos ao longo do seu percurso na instituição $\left(\right.$ INFOMONEY, 2011) ${ }^{36}$. É essa a reserva da iniciativa do proponente, evitando-se a sua intrusão nos domínios estritos do seu superior, como a apresentação de números ou dos termos do acordo ${ }^{37}$

O espaço e tempo da conversa são fatores igualmente ponderados, de forma a garantir-se alguma privacidade, o momento certo "em que o ambiente esteja mais calmo e o chefe descontraído" (COMO ABORDAR..., [s.d.]) $)^{38}$ e, em última análise, uma maior descontração - "Se o seu chefe notar que está nervoso, será mais fácil lhe recusar o pedido"(Ibid). A sua recusa, por outro lado, deve ser trabalhada de forma estratégica, podendo suscitar uma contraproposta, como a frequência de cursos e de ações de formação. Em nenhum momento, contudo, o trabalhador é aconselhado a uma resposta mais impetuosa: "Caso a empresa ou chefe o convença de que o momento não é de ajuste, não faça escândalo ou recue na sua produção, mas continue igual. Um pedido de aumento é sempre um alerta para que o chefe veja a aspiração daquele colaborador em ganhar mais". No máximo, segundo as recomendações do docente de gestão de RH Cristiano Luiz Rosa, há que repensar "a carreira dentro daquela companhia" (apud INFOMONEY, 2011). Na negociação das férias, além do ajuste das datas, sugere-se o prévio cumprimento de todos os prazos e a oferta de "horas extras no trabalho. Por exemplo, se habitualmente sai às seis da tarde, saia, duas ou três vezes por semana, às sete. Se for uma pessoa dedicada ao que faz, será quase impossível ser recusado" (COMO ABORDAR..., [s.d.] $]^{39}$.

Quando confrontada com uma depressão económica mundial, a anuência a essa política de recomendações assume uma premência acrescida. No entanto, a adversidade tende a ser vista como um difícil e turbulento terreno de oportunidades: 
${ }^{40} \mathrm{~A}$ CRISE pode ser o passo seguinte para poder subir na carreira.

iSabe, [S.I.], [s.d.]. Disponível em: $<$ http://bit.ly/2jfD5SE>. Acesso em: 15 dez. 2011. Artigo com ligação na página de Facebook da Randstad a 31 ago. 2011.
A crise pode ser sinónima de oportunidade de desemprego, mas também pode significar progressão na carreira. As crises alteram a perceção do mercado em quase todas as áreas, e isso exige novas competências, maior adaptabilidade e flexibilidade em termos de abordagem da nova situação. É aqui que reside a sua oportunidade para começar um novo sentido para a sua carreira, sem se deixar abater pelas incertezas ou dificuldades" 40 .

\section{Conclusão}

A componente prática das "dicas" e conselhos disponibilizados carrega consigo a defesa de uma ontologia, cumprida em vários passos enumerados, um a seguir ao outro. No primeiro passo, o CV, a sua elaboração recorda-nos dos preceitos da confissão religiosa e a sua atenção aos atos categorizados enquanto pecados. Longe da exposição abrangente e detalhada sobre a sua vida, ao confessor, como defende Michel Foucault, exige-se "que nos diga a nossa verdade ou antes, pedimos-lhe que diga a verdade profundamente penetrada por esta verdade de nós próprios que julgamos possuir em consciência imediata" (FOUCAULT, 1994: 74).

A divulgação realizada pelo $\mathrm{CV}$ ou na entrevista de trabalho é atravessada por esse discurso verdadeiro sobre si próprio, sugerindo-se uma autoavaliação com base nos critérios emanados pelas indústrias dos recursos humanos e pelo mercado de trabalho. A ocultação de uma experiência profissional negativa, causada por uma má relação com o colega ou com o superior, não é meramente instrumental, como se estivéssemos num jogo, constituindo antes um segredo de algo que nunca deveria ter acontecido. E, como defende A. W. Metcalfe, "se prudentes, eles não irão confessar (alto e bom som) certas fraquezas. Contudo, ao chegar a esta prudente decisão, eles acabam por se avaliar a si mesmos à medida de um empregador tornado Deus" (1992: 634).

Podemos sempre argumentar, com Erving Goffman (1993: 19), a distância entre o eu que apresenta e o eu apresentado, compreendida por um ciclo "potencialmente indefinido de simulação, descoberta, falsas revelações e redescobertas". Apesar de o trabalho corresponder àquele domínio onde a interiorização de comportamentos gera um "afastamento de si próprio" (Ibid.: 101), o seu agente sempre conseguiu refugiar-se em pequenas capelas, onde poderia resguardar-se do peso da instituição e cumprir um reportório minimamente seu.

Porém, existe uma tendência para a perpetuação dos processos de avaliação ao longo de toda a vida ativa do trabalhador, como se a lógica do panóptico se alargasse para lá do espaço físico de empresa e tornasse a existência dessas regiões de retaguarda cada vez mais difícil. Concebido inicialmente por Jeremy Bentham, o panóptico, como analisou mais tarde Michel Foucault, era um dispositivo de vigilância que permitia ver-se sem se ser visto a fazê-lo. Entre os observados, o reconhecimento da existência de tal aparelho significava a indução de "um estado consciente e permanente de visibilidade que assegura o funcionamento automático do poder" (FOUCAULT, 2001: 167). A sensação de permanente observação, independentemente de se estar a ser realmente ou não, faz com que não seja "necessário recorrer à força para obrigar o condenado ao bom comportamento, o louco à calma, o operário ao trabalho" (Ibid.: 167).

A integração do indivíduo nas redes sociais, como o Facebook a título de exemplo, poderá representar a expansão da lógica do panóptico para lá do espaço físico da empresa, aquilo que Massimo de Angelis designa de Panóptico fractal. Este não se limita a ser constituído por uma multiplicidade de panópticos, algo que já era patente na sociedade disciplinar descrita por Foucault. A grande novidade reside, sim, no facto de os inspetores passarem a ser igualmente inspecionados e dos inspecionados passarem a ser igualmente inspetores. Embora, como observámos, a figura do chefe seja ainda prevalecente, o recurso a dispositivos baseados numa opinião coletiva - do peer review ao team-building - fazem 
de 'todos os 'agentes' participantes [...] partes constituintes do que Bentham designava de 'força inspetiva'" (ANGELIS, 2007: 220). Em última análise, podemos admitir que a reconfiguração das funções de autoridade, integrada à formação e ao aconselhamento de trabalhadores (o coaching), incluem a avaliação da própria chefia à luz dos resultados obtidos pelos seus subordinados, entre outros critérios.

A sofisticação do olhar avaliador sobre o trabalhador, um olhar que também é o seu, assinala a passagem de sociedades disciplinares a sociedades de controlo. Estas, segundo Gilles Deleuze (2003: 244), funcionam por via da modulação, um processo de "curto prazo e de rotação rápida, mas também contínuo e ilimitada". Ou seja, uma flexibilidade e adaptação na resposta às várias vicissitudes que permitem atravessar as várias instituições e cobrir todos os cantos recônditos da sociedade.

Nesse sentido, a precariedade laboral é mais do que um fenómeno ou uma consequência social: a sempre presente possibilidade de se retornar ao mercado de trabalho leva o trabalhador a encetar as opções necessárias à manutenção da sua sobrevivência: não confrontar o chefe, procurando contrabalançar as suas falhas; aceitar a recusa de um pedido salarial; realizar horas extraordinárias em troca do direito legal a férias; oferecer um ombro amigo ao seu chefe. A precariedade poderá assim ser encarada como uma estratégia de modulação, destinada a garantir, como se pode ler, um trabalhador disposto a atender à percepção do mercado.

\section{Referências}

ANGELIS, M. The beginning of history. London: Pluto, 1997.

BARROSO, R. P. Vídeo-CV: procurar emprego na era da imagem. 2012. Disponível em: <http://bit.ly/2jrbeAc>. Acesso em: 14 dez. 2011.

BENVENISTE, É. O homem na linguagem. Lisboa: Veja, 1992.

BOURDIEU, P. O que falar quer dizer. Lisboa: Difel, 1998.

BOUTANG, Y. M. Le capitalism cognitive: la nouvelle grand transformation. Paris: Éditions Amsterdam, 2008.

CARTA de apresentação. Expressoemprego, 1 jun. 2015. Disponível em: <http://bit.ly/2jM3ZCH>. Acesso em: 14 dez. 2011.

CATARINA Horta, Directora RH da Randstad Portugal em entrevista na RTP. Reprodução: Randstad Portugal; YouTube. 2 nov. 2011. (5 min), son., color. Disponível em: <http://bit.ly/2jMA3q5>. Acesso em: 28 dez. 2011.

COMO arranjar emprego "à francesa". Cap Magellan, [S.I.], 2011. Disponível em: <http://bit.ly/2jEgyMj>. Acesso em: 12 nov. 2011.

COMO procurar emprego. Portal do IEFP, [s.d.]. Disponível em: <http://bit.ly/2iPySlu>. Acesso em: 19 dez. 2011.

DELEUZE, G. Post-scriptum sobre as sociedades de controlo. In: Conversações. Lisboa: Fim de Século, 2003. p. 239-246.

DOMINGOS, N. O futebol e o trabalho. In: NEVES, J.; DOMINGOS, N. (Org.). A época do futebol. Lisboa: Assírio e Alvim; Arquivo Fotográfico Municipal, 2004. p. 305-328.

FOUCAULT, M. A arqueologia do saber. Coimbra: Almedina, 2005. 

1994.

A vontade de saber: história da sexualidade I. Lisboa: Relógio D’Água,

Vigiar e punir: história da violência nas prisões, Petropólis: Editora Vozes, 2001.

GOFFMAN, E. A apresentação do Eu na vida de todos os dias. Lisboa: Relógio D’Água, 1993.

ILES, P.; SALAMAN, G. Recruitment, selection and assessment. In: STOREY, J. (Ed.). Human resource management: a critical text. London: Routledge, 1995. p. 202-233.

INFOMONEY. Saiba o que realmente justifica um aumento de salário. Administradores, [S.I.], 2011. Disponível em: <http://bit.ly/2jeZWhC >. Acesso em: 29 nov. 2011.

MATEUS, C. Como causar uma primeira boa impressão. Expressoemprego, [S.I.], 2011a. Disponível em: <http://bit.ly/2j8cZyY>. Acesso em: 28 dez. 2011.

Currículos que abrem portas. Expressoemprego, [S.I.], 2011b. Disponível em: <http://bit.ly/2ikA5VR>. Acesso em: 26 nov. 2011.

O poder das redes profissionais. Expressoemprego, [S.I.], 2011c. Disponível em: <http://bit.ly/2jMoLC8>. Acesso em: 29 dez. 2011.

MCKINLAY, A.; TAYLOR, P. Through the looking glass: Foucault and the politics of production. In: MCKINLAY, A.; STARKEY, K. (Ed.). Foucault, management and organization theory. London: Sage, 1998. p. 173-190.

MENDES, S. Dê-se bem com o seu chefe. iSabe, [S.I.], [s.d.]. Disponível em: <http://bit.ly/2jfndjl>. Acesso em: 21 nov. 2011.

METCALFE, A. W. The curriculum vitae: confessions of a wage-labourer. Work, Employment \& Society, London, v. 6, n. 4, p. 619-641, dec. 1992.

NOVO emprego - Dicas para o jovem profissional - Palestrante Mario Persona. Reprodução: tvbarbante; YouTube. 22 ago. 2009. (9 min), son., color. Disponível em: <http://bit.ly/2jfilFu>. Acesso em: 15 nov. 2011.

O PRIMEIRO passo para procura de emprego: o Curriculum Vitae. Revista Randstad, [S.I.], ano 1, n. 2, 2010. Disponível em: <http://bit.ly/2j8kmGr>. Acesso em: 27 out. 2011.

O VELHO CV já devia ter morrido: entrevista com Filipe Carrera. SapoTEK, [S.I.], 2011. Disponível em: <http://bit.ly/2inEKkQ>. Acesso em: 7 dez. 2011.

PALAVRAS a evitar. SapoEmprego, Lisboa, [s.d.]. Disponível em: <http://bit.ly/2j8iUnC>. Acesso em: 20 dez. 2011.

PEREIRA, R. Sabe o que é o BranchOut? Você pode achar seu próximo emprego pelo Facebook. Época, São Paulo, 24 jun. 2011. Disponível em: <http://glo.bo/2ikE2tO>. Acesso em: 14 dez. 2011.

PETIZ, J. Sete conselhos para sobreviver à entrevista e sair de lá com emprego. Universia, [S.I.], 21 jan. 2011. Disponível em: <http://bit.ly/2j8dk4w>. Acesso em: 21 nov. 2011.

POSTURA de sucesso. SapoEmprego, Lisboa, [s.d.]. Disponível em: <http://bit.ly/2jMCbOA>. Acesso em: 2 nov. 2011.

ROSE, G. Visual methodologies. London: Sage, 2002. 
TEAM building.SapoEmprego, Lisboa, [s.d.]. Disponível em:<http://bit.ly/2io8NJr>. Acesso em: 23 dez. 2011.

TORRES, C.; DUARTE, A. Coaching em contexto organizacional. Negócios, [S.I.], 2011. Disponível em: <http://bit.ly/2jRAiMl>. Acesso em: 15 dez. 2011.

UM CURRICULUM competitivo. SapoEmprego, Lisboa, [s.d.]. Disponível em: <http://bit.ly/2io8QVD>. Acesso em: 26 dez. 2011.

VENDA as suas ideias. SW, [S.I.], [s.d.]. Disponível em: <http://bit.ly/2j8cx3J>. Acesso em: 15 dez. 2011. 